\title{
Isolated Mucocele in an Infraorbital Ethmoidal Cell-Haller Cell: A Unique Presentation
}

\author{
Satyawati Mohindra, Shruti Dhingra
}

\section{ABSTRACT}

Haller cell was first described by 18th century S wiss anatomist Albrecht von Haller.

Haller cells make up the posterior and superior wall of the ethmoid infundibulum. They can cause obstruction of ethmoidal infundibulum after enlargement. Isolated infection of the Haller cell is usually very rare and should be suspected in patients with visual complaints or facial pain. Diagnosis can be made on radiology.

Here, we report a patient with complaints of left-sided eye pain for the last 4 months which was finally diagnosed as Haller cell mucocele and successfully managed via endoscopic marsupialization.

Keywords: Haller cell, Infraorbital ethmoidal cell, Mucocele.

How to cite this article: Mohindra S, Dhingra S. Isolated Mucocele in an Infraorbital E thmoidal C ell-Haller Cell: A Unique Presentation. Clin Rhinol An IntJ 2013;6(1):44-46

\section{Source of support $\mathrm{Nil}$}

Conflict of interest: None declared

\section{INTRODUCTION}

A pneumatized infraorbital ethmoid cell, also known as a Haller cell, was first described by 18th century Swiss anatomist Albrecht von Haller. Haller cells make up the posterior and superior wall of the ethmoid infundibulum. When they enlarge, they can cause obstruction of the ethmoid infundibulum and lead to maxillary sinusitis. Isolated infection of the Haller cell is usually very rare and should be suspected in patients with visual complaints or facial pain. The diagnosis of a Haller cell may be difficult on endoscopy due to its location and can only be identified on radiology. We describe a rare case of isolated $\mathrm{Haller}$ cell mucocele.

\section{CASE REPORT}

A 39-year-old female patient presented to the ENT clinic with complaints of left-sided eye pain for the last 4 months. She had no other complaints of associated headache, nasal obstruction or postnasal drip. The patient underwent a complete ophthalmological examination including visual acuity, fundoscopy and ocular muscle functions. No alteration of these parameters was observed. $\mathrm{N}$ asal endoscopy with a $0^{\circ}, 4 \mathrm{~mm}$ telescope revealed deviation of the nasal septum toward the right side and a widely patent middle meatus on the left. Waters' view of the paranasal sinuses, done elsewhere and brought by the patient, showed haziness of the left maxillary sinus.
Noncontrast computed tomographic scans of the paranasal sinuses (axial and coronal cuts, Figs $1 \mathrm{~A}$ and $\mathrm{B}$ ) and contrast-enhanced M RIs (coronal and sagittal cuts, Figs $2 \mathrm{~A}$ and $\mathrm{B}$ ) were done. Computed tomographic (CT) scan reveal ed a soft tissue density in the roof of the left maxillary sinus. The ostiomeatal complex was normal and so was the rest of the maxillary sinus. The integrity of the lamina papyracea was maintained and there was no evidence of prolapsed orbital fat. Contrast-enhanced MRI showed evidence of a fluid-filled aberrant air cell in the roof of the left maxillary sinus which was hyperintense on $\mathrm{T} 2$ and
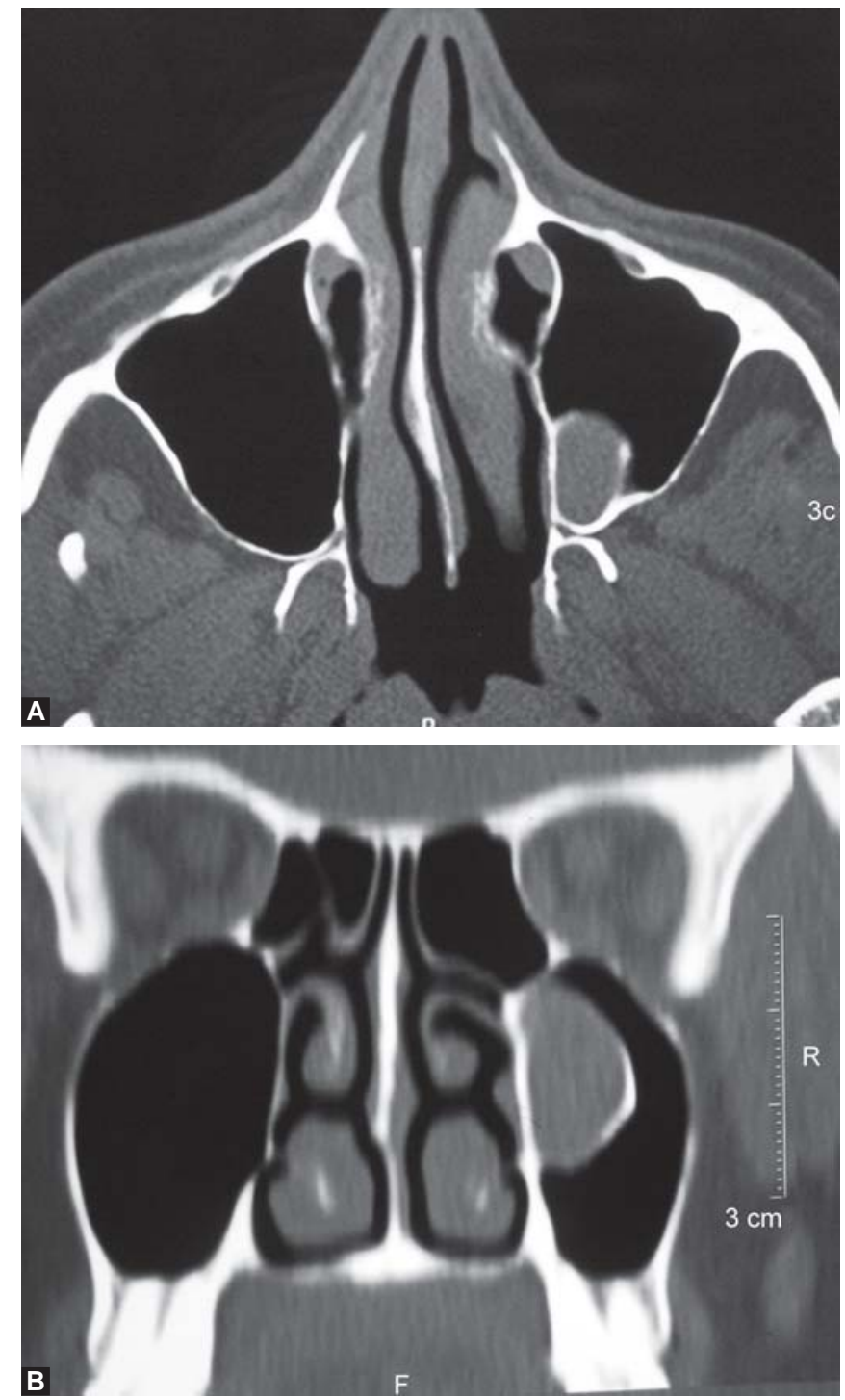

Figs $1 \mathrm{~A}$ and B: NCCT PNS axial and coronal cuts showing a soft tissue density in the roof of the left maxillary sinus and a patent ostiomeatal complex 


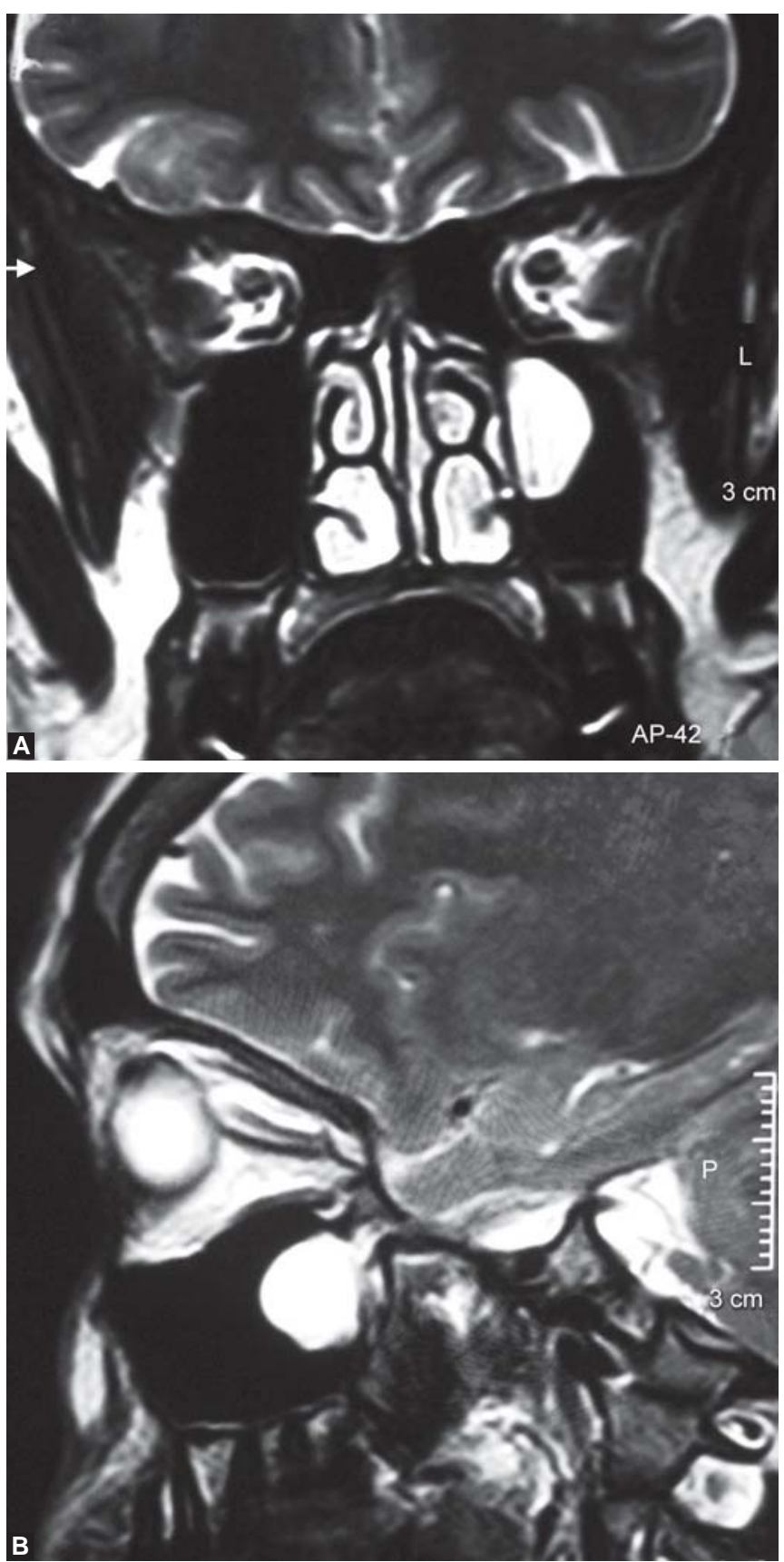

Figs 2A and B: Contrast-enhanced MRI showed evidence of a fluid-filled aberrant air cell in the roof of the left maxillary sinus

isointense on T1-weighted images, with subtle postcontrast enhancement. There was no evidence of any mucosal thickening or polyp in the maxillary sinus. Bilateral optic nerve canals were normal. There was no other intraorbital abnormality. Based on these findings, a diagnosis of mucocele of the Haller cell was made. The patient underwent an endoscopic clearance of the disease. U sing a $30^{\circ}$ endoscope, the cell was resected and was found to contain thick, yellow pus (Fig. 3). Following the procedure, the patient has remained symptom free for the past 24 months now.

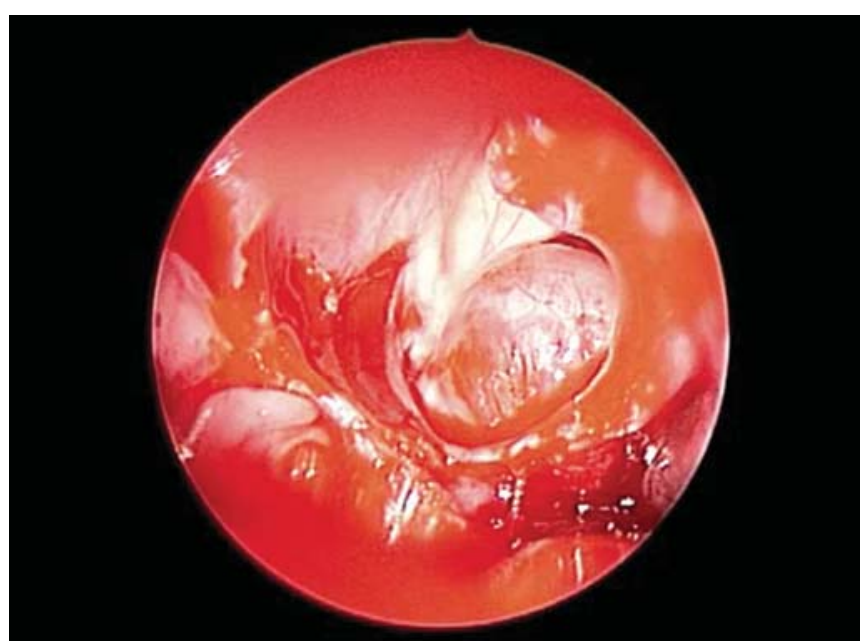

Fig. 3: A $30^{\circ}$ endoscopic view of a fluid-filled cell in the posterior part of the roof of the left maxillary sinus

\section{DISCUSSION}

Haller cell, presently called, orbitoethmoidal cell according to new terminology, was first described by a Swiss anatomist Albrecht von $\mathrm{Haller}{ }^{1}$ It arises as an extension of pneumatization of the ethmoidal cells; $88 \%$, arising from the anterior and $12 \%$ from the posterior group. ${ }^{2}$ In our case, it seemed to be a part of the posterior ethmoidal group. Haller cell is not seen endoscopically due to its lateral location but can be identified on radiology. Inflammation of the Haller cell is common in ethmoidal and maxillary sinus infection but an isolated mucocele of this cell is very uncommon. One such case has been reported by L uxenberger et al. ${ }^{3} \mathrm{~A}$ differential diagnosis of neuroma of the infraorbital nerve, cavernous hemangioma of the infraorbital canal or mucocele of the septated compartment of the maxillary sinus must be kept.

M ucoceles rising within the septated compartments in the maxillary sinus or in Haller cells will show a thin bony septum between the lesion and the normal maxillary sinus cavity on CT scans. They are usually located in the roof of the maxillary sinus as against extra-antral mucoceles which are usually found to arise from the floor of the sinus and push the floor of the antrum superiorly. ${ }^{4}$ I solated infection of the Haller cell can cause headache and ocular pain. It can also block the ethmoidal infundibulum and cause maxillary sinusitis. A mucocele of the Haller cell can expand slowly, erode the roof of the maxillary sinus and extend into the orbital cavity. Expansion of the mucocele arising from posteriorly located Haller cell, when invading the orbit, can cause ophthalmological symptoms of proptosis, diplopia, ptosis, visual or oculomotor disturbances and pain in the eye. It is therefore important to identify and remove them if symptomatic. A transnasal endoscopic 
approach is usually undertaken but visualization of the disease in the anterior-most portion of the maxillary sinus, close to the infraorbital margin, may be difficult and access to the Haller cell may require a mini Caldwell-Luc approach.

\section{REFERENCES}

1. von Haller A. First lines of physiology. Edinburgh: O. Penniman \& Co 1803.

2. Kainz J, Braun H, Genser P. Haller's cells: Morphologic eval uation and clinico-surgical relevance. L aryngorhinootologie 1993; 72:599-604.

3. L uxenberger W, A nderhuber W, Stammberger $\mathrm{H}$. M ucocele in an orbitoethmoidal (Haller's) cell (accidently combined with acute contralateral dacrocystitis) R hinology 1999;37:37-39.
4. Han M H, Chang KH, et al. Cystic expansile masses of the maxilla: Differential diagnosis with $C T$ and MR. Am J Neuroradiol 1995;16:333-38.

\section{ABOUT THE AUTHORS}

\section{Satyawati Mohindra (Corresponding Author)}

A ssociate Professor, Department of Otolaryngology and HeadNeck Surgery, Postgraduate Institute of M edical Education and Research, Chandigarh, India, Phone: 09914209765, e-mail: satyamohindra@gmail.com

\section{Shruti Dhingra}

Senior Resident, Department of Otolaryngology and Head-Neck Surgery, Postgraduate Institute of M edical Education and Research Chandigarh, India 